\title{
Descolonialización epistémica. Aportes del pensar andino abyayalanse a la filosofía
}

\author{
Epistemic-decolonization. \\ Contributions of andinean abyayalanse thought to philosophy
}

\section{Descolonização epistêmica.}

Aportes do pensar andino abyayalanse à filosofia.

Fecha de entrega: 10 de septiembre 2015

Fecha de evaluación: 15 de octubre de 2015

Fecha de aprobación: 25 de noviembre de 2015

Israel Arturo Orrego Echeverría*

\section{Resumen}

El presente trabajo tiene por objeto reflexionar sobre el carácter filosófico del pensar andino abyayalense, explicitar las características de una racionalidad senti-pensante y relacional que supere las metafísicas subjetivas y, finalmente, ayudar a construir una epistemología decolonial latinoamericana. El logro de estos objetivos se hará en diálogo con la propuesta de la ontología existencial del filósofo alemán Martín Heidegger.

Palabras clave: pensar, relacionalidad, Epistemología, Filosofía, Andes.

Doctorando en Filosofía (USTA), Magister en Filosofía Latinoamericana, Especialista en Educación y Cultura Política, Filósofo, Licenciado en Ciencias Teológicas, Catedrático de la facultad de filosofia de la Universidad Libre de Colombia, Docente-Investigador de la Corporación Universitaria Minuto de Dios (UNIMINUTO), Bogotá, Colombia. Correo electrónico: arturo.orrego@gmail.com 


\section{Abstract}

This work intends to reflect on the philosophical characteristics of the Andean Abyayalense thought and also to express characteristics of a "feeling-thinking" and relational rationality which can overcome metaphysical subjectivity and finally, help to build a non-colonial Latin American epistemology. The achievement of these objectives will be carried out in dialogue with the proposal of existential ontology of German philosopher Martín Heidegger.

Keywords: Thought, relationality, epistemology, philosophy, Andean region.

\section{Resumo}

Este trabalho tem como objeto refletir sobre o caráter filosófico do pensar andino abyayalense, explicitar as características de uma racionalidade senti-pensante e relacional que supere as metafísicas subjetivas e finalmente ajudar a construir uma epistemologia decolonial latinoamericana. Atingir estes objetivos se fará em dialogo com a proposta de ontologia existencial do filosofo alemão Martín Heidegger.

Palavras-chave: Pensar, relacionalidade, Epistemologia, Filosofia, Andes.

“[...] Razón por la cual una fuerte emoción no nos deja ver el mundo, o un mundo que nos acosa no nos da tiempo para emocionarnos"

(Kusch, 2003, p. 45)

El problema epistemológico indígena, particularmente en el contexto andino, requiere la reflexión de elementos fundamentales dentro del "sistema" mismo de comprensión del mundo andino como un todo -lo que algunos denominan cosmovisión-, pues de lo contrario la mera referencia a nociones epistemológicas quedará vedada del horizonte comprensivo en el que se podrá rastrear su sentido filosófico más profundo. Dicha aproximación al fenómeno epistemológico andino remite necesariamente al 
intento de su comprensión dentro de un marco categorial y "racional” que sea propio y coherente con el sistema "epistemológico" a estudiar.

\section{Acerca de lo andino}

El concepto "andino" suele tener múltiples interpretaciones que no en todos los casos enriquecen el sentido del mismo, máxime desde un abordaje filosófico. Desde ciertas perspectivas, lo andino no requiere mucha aclaración pues se suele reducir a una determinada categoría limitada y delimitada por una referencia a lo etnográfico y sociológico. No se pretende decir que estos abordajes no aporten a la comprensión de lo "andino", sino que tomados de manera parcial -como es propio de la epistemología de dichas ciencias- no logran su cometido.

De manera parcial podríamos delimitar lo andino a una categoría que hace referencia a un determinado territorio y/o espacio geográfico ubicado en América del Sur y caracterizado por ser una región montañosa (Cordillera de los Andes) con una altitud promedio de 4000 metros. Dicha región se extiende desde Venezuela, pasa por Colombia, Perú, Bolivia, hasta el norte de Chile y Argentina: Estas características son de importancia en el análisis filosófico, dado que como menciona el filósofo suizo-alemán, Josef Estermann:

\footnotetext{
El espacio geográfico y topográfico de los Andes es determinante en parte para la elaboración de un pensamiento filosófico propio, tal como lo eran también - mutatis mutandis- el paisaje costeño en Jonia para la filosofía griega o la región fluvial del Ganges para la filosofía índica. Por ejemplo, no impactan como categorías primordiales (como en Jonia) la reflexión sobre la inmensidad del mar, la dialéctica entre tierra firme (constancia) y aguas movibles (mutabilidad), ni (como en la India) la periodicidad de los monzones [...] sí juegan un rol importante la precariedad de la tierra y del agua, la dialéctica entre arriba y abajo (por la topografía) [...] (Estermann, 2006, p. 60).
}

Muy ligado a una comprensión de lo andino con un determinado espacio geográfico, podríamos también interpretar dicho concepto en relación con las formas colectivas de vivir de una determinada población. Lo andino, entonces, es entendido aquí como “cultura" (Estermann, 2006, p. 61), si se tiene en cuenta que los modos de vivir -de "hacer las cosas" - no son más que la adaptación de los colectivos sociales, de las comunidades, al entorno geográfico en el cual deviene su supervivencia. 
Ahora bien, un tercer abordaje de lo "andino" que en nada excluye a los anteriores, pero que ciertamente permite comprender dicho concepto desde una perspectiva más amplia para los efectos del análisis filosófico, es aquel que comprende lo andino en sentido del "ser humano andino" o del "pueblo andino", es decir, como una categoría étnica. Uno de los malos entendidos con respecto a lo andino desde el punto de vista etnológico tiene que ver justamente con una concepción indigenista del mismo, que reduce la categoría en discusión a una aparente "raza pura" indígena, sea esto en la versión del incaismo y/o cualquier ismo ${ }^{1}$ indigenista, tan de moda en la actualidad.

Lo andino, como recuerda Estermann, es mucho más amplio que lo incaico, pues aún continua siendo un término de una realidad vigente. Al respecto debe recordarse que "el imperio Incaico siempre ha sido una cultura imperialista [...] para la cultura tiwanacota" (2006, p. 71). Baste recordar las descripciones de Joan de Santa Cruz Pachacuti Yamqui Salcamaygua, al referirse a los demás indios del Tawantinsuyo: ${ }^{2}$

Y como en general los indios eran tan idiotas y torpes, con pocas facilidades; por ser tan haraganes los escogieron por su pacarisca y pacarimusca [...] así esta gente idiota y sin letras fueron engañados por los demonios y diablos con no poca facilidad [...] este Inka (Manco Capac) había mandado que ataran las cabezas de las creaturas para que sean simples y sin ánimo, porque los indios de cabeza grande y redonda, suelen ser atrevidos [...] y desobedientes (Duvilios e Itier, 19993, 199; f. 9.)³.

Así, lo incaico hace alusión a un determinado imperio y territorio, este siempre tiene una connotación anamnética - $\alpha v a \mu \nu \eta \sigma \iota \varsigma_{-}$, en cuanto pretende no sólo idealizar un pasado (ciertamente no poco documentado en la actualidad), sino que además

1 Al respecto de dichos abordajes desde una perspectiva incaista pueden observarse los trabajos de:Juvenal Farfán (1994); Maria Luisa Rivara de Tuesta (1992); Victor Díaz Guzmán (1991); Mario Mejía Huamán (2005).

2 Tawantinsuyu es el término quechua que literalmente significa "las cuatro regiones" y hace referencia al territorio dominado por el imperio Inka que iba desde Venezuela y Colombia, hasta el noreste argentino, ocupando una extensión de aproximadamente 3000000 km (Estermann, 2006, p. 69).

3 Texto original: $Y$ como en general los yndios eran tan idiotas y torpes, con poca façelidad y oir ser tan haraganes los escogieron por sus pacarisca o pacarimusca [...] así a esta gente idiotas y sin letras, los demonio y diablos hapiñuños los engañaron con poca façeledad [...] este mismo ynca los había mandado que ataran las cabeças de las creaturas para que sean simples y sin ánimo, porque como los yndios de gran cabeça y redondo suelen ser atribidos, para cualquier cossa mayormente son inobedientes. 
carece de una conexión directa en el mundo actual, pero presente aún en la lengua quechua. No sucede lo mismo con la connotación de lo "andino" que sigue existiendo más allá de la relación con el Tawantinsuyo la etnia de los Inkas ${ }^{4}$, es decir, vinculado con un periodo histórico determinado (1200 d. C. - 1783 d. C. aprox.). Lo andino, superando cualquier "purismo" antropológico y/o romantización etnológica, así como todo abordaje posmoderno de los estudios culturales, está presente en muchos elementos de la tradición inca, pero no se reduce a la misma. Por el contrario, lo incaico es una más de las expresiones de lo andino, por lo que no podemos hacer una escisión entre lo propiamente andino -lo "puramente" andino- y lo inca, sin caer en errores hermenéuticos.

Lo andino debe ser comprendido, en consecuencia, como un fenómeno multicultural -también multiétnico-, no limitado meramente, aunque sí más evidente en las poblaciones indígenas de América Latina. Lo andino es "un pensamiento vivo y vigente en la actualidad, con raíces históricas muy hondas, inclusive y ante todo en el periodo de la cultura incaica" (Estermann, 2006, p. 73).

\section{Fundamentos de una epistemología andina}

Pensar en una epistemología andina es algo más complejo que en la filosofía occidental, por varias razones, entre otras, por los escasos materiales bibliográficos que permitan dilucidar las perspectivas andinas del concepto a estudiar. Por otra parte, la categoría misma de "concepto" es ajena al pensar indígena, no por adolecer este de términos para expresar las ideas, representaciones mentales y experiencias del sujeto, sino por la idea logo-céntrica que tras la explicación del mundo por medio del concepto se esconde -ello no quiere decir que el pensamiento andino sea preconceptual-. En otras palabras el saber andino es un saber que no se soporta ni se expresa principal, ni necesariamente por medio del concepto, sino que integra en una realidad mucho más amplia las intuiciones y experiencias que fundamentan su epistemología.

4 Recuérdese que en las narraciones de Pachacuti (Duvilios, P \& Itier, 1993), los Incas son descendientes de Apo Tampo quien recibe directamente de las manos de la legendaria figura de Tunopa el bordón de oro, después de haber sido rechazado su mensaje en otras poblaciones. Los descendientes de Apo Tampo, particularmente Manco Capac Inca, serán los formadores de la nueva estirpe gobernante de los Incas. 
Se hace imprescindible, por lo tanto, reflexionar sobre lo filosófico del pensar andino. Es más, reflexionar sobre lo filosófico del pensar mismo, pues como bien lo recuerda Martín Heidegger, en Carta sobre el humanismo (2007), la filosofía de nuestro tiempo, en los tiempos de la técnica y de la metafísica del sujeto, característica por demás de la modernidad-colonialidad, ya no piensa sino que se ocupa con la filosofía. Y este ocuparse técnico y logo-céntrico, no es otra cosa que el olvido del ser y la caída del Dassein en el conocer y describir meramente los entes, haciendo de estos el primado del saber y de su quehacer (Heidegger, 2005). El pensar, en cambio, no se limita al lenguaje que preso de la gramática y de la lógica, solo puede nombrar entes bajo los cuales se pretende establecer una cierta jerarquía epistémica del sujeto humano, el pensar, tal como lo entrevió el filósofo alemán requiere no solo el proceso fenomenológico de suspender los juicios y categorías previas para ir la 'cosa' misma, sino que incluso este " $[\ldots]$ tiene que aprender previamente a existir prescindiendo de nombres" (2007, p. 263), pues antes de hablar, el filósofo debe dejarse interpretar por el ser, para que en el "cuidado", sin el cual no hay pensar, el filósofo 'deje' ser al ser lo que es:

Sólo se conoce el actuar como la producción de un efecto, cuya realidad se estima en función de su utilidad. Pero la esencia del actuar es el llevar a cabo. Llevar a cabo significa desplegar algo hacia la plenitud de su esencia, guiar hacia ella, producere. Por eso, en realidad sólo se puede llevar a cabo lo que ya es. Ahora bien, lo que ante todo "es" es el ser. El pensar lleva a cabo la relación del ser con la esencia del hombre. No hace ni produce esta relación [...] el pensar no se convierte en acción porque salga de él un efecto o pueda ser utilizado. El pensar solo actúa en la medida que piensa. Este actuar es seguramente el más simple, pero también el más elevado [...] (Heidegger, 2007, p. 259).

Más allá de la orientación ontológica del filósofo alemán, nos interesa aquí el estatuto filosófico, originario y primario del pensar, pues sobre este se abre la posibilidad de una filosofía amerindia decolonial, que no solo es guardada por los poetas y pensadores, como supuso Heidegger, sino que en sentido primario el pensar "nos lleva al ámbito de la memoria, el recogimiento y la gratitud" (Heidegger, 2008, p. 142); todas estas características muy presentes en el pensar andino, tanto en su volcarse poético-celebrativo y ritual al mundo, como en el pensar mismo como acto de "dejar ser, siendo-estando" (Orrego, 2014). 
Si no es el pensar el punto de partida, sino la ratio intelectiva, las descripciones y categorizaciones hechas en el mundo andino no pasarían de ser reflexiones de orden sociológico, antropológico y cultural, pero no propiamente filosóficas. Ahora bien, lo anterior no puede reducirse a poner en un marco categorial propio de la racionalidad occidental las nociones epistemológicas andinas, pues, por el contrario, el fenómeno epistemológico andino será en lo posible dilucidado desde su propio horizonte de sentido - Sitz im leben-.

El problema de lo que es o no la filosofía sigue siendo campo fértil de discusión para Occidente mismo, cuanto más para la reflexión en el ámbito andino. Sin embargo, y a pesar de la evidente dificultad para dar a la filosofía una única tarea o peor aún un único origen que en muchos casos se remite al pensamiento griego y en la modernidad al germano, gran parte de la lógica imperante y colonial afirma como "filosofía" únicamente a aquellas reflexiones que se ajusten a las determinaciones dadas por la racionalidad hegemónica, en este caso la racionalidad occidental. Lévy Bruhl (2003) es quizá el ejemplo más particular de esa comprensión reduccionista y colonialista del saber filosófico; incluso llegó a considerar al pensamiento americano como "primitivo".

Así, otras aproximaciones a la realidad como las indígenas son negadas; máxime tratadas como "etno-filosofías". Lo anterior se evidencia no sólo desde las perspectivas occidentales, sino desde el interior mismo de la reflexión latinoamericana, la cual se ha caracterizado por repetir las estructuras de pensamiento que son ajenas a la experiencia y racionalidad de los pueblos desde donde se enuncia el discurso filosófico. En consecuencia, la labor filosófica se ha convertido en la repetición de ideas y conceptos -sea a manera de historia de las ideas y/o recepción del pensamiento filosófico occidental en América- de las tradiciones europeas y occidentales; lo que actualiza y ratifica paradójicamente la conocida percepción hegeliana sobre América de que "Was bis jetz sich hier ereignet, ist nur der Widerhall der Alten Welt und der Ausdruck fremder Lebendigkeit” (Hegel, 1970, p. 114).

El filósofo peruano Salazar Bondy (1978, p. 24), había advertido que la iniciativa filosófica en América a través de sus diferentes etapas da muestra de una conciencia enajenada y enajenante, producto de la inautenticidad cultural a las que nuestros

5 "Lo que aquí sucede hasta el momento, es sólo el eco del Mundo Viejo y la expresión de una vitalidad foránea" (Hegel, 1986). 
pueblos han sido sometidos, recibiendo «una imagen superficial del mundo», lo que supone nada menos que una imposición de carácter epistémico.

Ahora bien, una pretendida postura filosófica y cultural quiere asignar y confinar el pensar filosófico a unos exclusivos y determinados orígenes culturales y geográficos, olvidando así que "filosofía" tiene que ver también con "amor", es decir, con una experiencia existencial; y en segundo término tiene que ver con "sabiduría", lo que subraya el nexo existencial (Estermann, 2006, p. 27; Heidegger, 2007). Sin embargo, las interpretaciones modernas de lo que es la filosofía se han ido apartando con su rigidez y logo-centrismo de estas acepciones que representan y caracterizan el pensar mismo, olvidando no solo el ser, como lo anticipa el filósofo alemán, sino también el sentido mismo de lo que es la filosofía. Aquí radica justamente un aporte fundamental del pensar andino a la filosofía en América Latina.

Otra característica de la racionalidad moderna es la separación entre teología y filosofía, como también la conocida tensión entre el mythos y el logos, aparentemente dada por los primeros filósofos.

La "filosofía" se convertía, entonces, empezando con Platón, en "logología" o "noología", estudio distanciado y teórico del logos y nous. El amor pasional (eros y philia) inicial se enfriaba, y con él el compromiso personal con los problemas prácticos, políticos y existenciales. La filosofía poco a poco dejaba de ser interpretación apasionada de la experiencia vivencial y se convertía en "teoría" acerca del ser (ontología), del conocer (epistemología) y hasta en interpretación de la interpretación (historiografía) (Estermann, 2006, p. 22).

Pierde la filosofía en Occidente aquella característica del sentimiento mismo que inundaba la labor filosófica, apartándose de la realidad de los pueblos y del compromiso con los mismos para comprenderse como racionalidad lógica, metodología sistemática, actitud antimitológica, analítica y demás.

La concepción occidental de la "filosofía", que se yuxtapone al pensamiento mítico, las cosmovisiones y Weltanschauungen, parecen haber nacido recién en la época postrenacentista. Se trata de una concepción reduccionista y excluyente, hasta el extremo que hoy día la misma filosofía en sus "batallas de repliegue" está a punto de perder su razón de ser, con la excepción de estudiar como ciencia "rumiante" su propia historia (historicismo) (Estermann, 2006, p. 24). 
Como esto último no puede ser el caso de la filosofía andina, justamente porque su pensar no se centra en la categorización conceptual, racional, analítica y "sistemática" de Occidente, sino en la experiencia misma y más justamente, como le llama El filósofo argentino Günter Rodolfo (2003) se expresa en lo sacramental y celebrativo, aspectos en los que la realidad adquiere otras dimensiones. Ello no quiere decir que el pensamiento y la reflexión de los Andes se hallen al margen de la inteligibilidad propia del concepto, sino que los marcos categoriales mismos son retomados desde otro horizonte comprensivo que Kusch ha llamado la lógica de la negación.

\section{El pensar indígena y la realidad simbólico-celebrativa}

Es bien sabido que la filosofía de raigambre occidental busca la verdad de la realidad -aspiración última de cualquier filosofía- sabiendo de antemano que esta no se presenta de manera inmediata y por ello requiere ser re-presentada de manera fidedigna a través del concepto, o por lo menos este ha sido, junto con la lógica, la manera predilecta de Occidente para re-presentar la verdad de la realidad.

Pues bien, cuando se trata de reflexionar en torno a la epistemología andina, se requiere pensar en las formas como en los Andes se re-presenta la realidad misma, pues si bien no es propiamente una mediación conceptual la que en este caso particular opera, es una mediación tanto o igualmente legítima a la de Occidente; el pensar dichas "re-presentaciones" andinas filosóficamente será la labor del filósofo en los Andes.

Kusch, al tratar de desentrañar el sentido del pensamiento indígena y popular, pasó largos años de su vida investigando la manera como funcionaba la "lógica" indígena andina. Coherente con las experiencias y expresiones que se propone evidenciar, en particular en la Teología Popular (2003), este pensador sitúa su reflexión en la cotidianidad ritual del pueblo indio, desde la experiencia ritual de Eucaliptus, que servirá de "texto" guía para desentrañar y comprender lo que podría ser una "lógica andina” y desde allí, interpretar sus nociones “epistemológicas".

Eucaliptus es un pueblo ubicado a $80 \mathrm{~km}$ de La Paz (Bolivia), y siendo una población no muy antigua, rápidamente se caracterizó por su crecimiento y actividad comercial, así como por ser principalmente una comunidad de transportadores de mercancías, razón por la cual era de esperarse que muchos aspiraran a conseguir un camión (y efectivamente lo hicieran). 
Ahora bien, el elemento central de la mención a Eucaliptus gira en torno al santuario instalado por un "hechicero" de la población cercana de Kellkata. Este santuario era usado para la sacralización de los camiones. En función de este ritual el santuario disponía de dos construcciones en medio de las cuales se situaba el vehículo: al lado izquierdo todo lo relacionado con la "Gloria" (elementos católicos) y a la derecha lo consagrado al Achanchu -deidad nefasta para los aimaras-. En cada uno de los lados del santuario y en una tercera mesa que correspondía a la parte del conductor, se disponía una serie de elementos de diversa índole como: semillas, cigarrillos, alimañas, piedras y hasta imágenes católicas, pero conservando estas últimas para el lado izquierdo, el de la "Gloria".

Kusch llama la atención sobre el hecho de que en los rezos del Tata Mauricio que correspondieron al lado izquierdo del santuario, en el calvario, la ceremonia era más fría que la dedicada al dios nefasto, Achanchu, este último era el dios al que se solicitaba el "uso favorable del camión" (2003, p. 608). Es evidente que para el filósofo argentino esta experiencia ritual en el santuario estaba cargada de una manera especial de pensar la realidad; de una forma diferente de relacionarse y comprender los objetos, en el particular, el camión.

El ritual de Eucaliptus permite al filósofo argentino percatarse de un elemento fundamental en el pensamiento -epistemología- indígena. A saber, que la experiencia del "sujeto" andino con el mundo de los objetos -fundamental en la epistemología occidental-, en el particular con el camión de Eucaliptus, difiere "radicalmente" de la experiencia de Occidente -Buenos Aires, en el caso del análisis kuschiano- con el mismo. Se pregunta además Kusch de dónde procede el complicado ritual del santuario o la concreta simplicidad del festejar con una cerveza. Al respecto menciona que:

[...] Esto nos hace pensar que en Buenos Aires la acción termina en el camión, y en Eucaliptus esa misma acción se prolonga en un área que trasciende a la cosa para integrarse en el mundo divino.

Nosotros decimos: "Ese es el camión, lo he comprado, entonces lo usaré". El campesino de Eucaliptus dirá: "Ese es el camión, lo he comprado, pero no sé si realmente podré usarlo, porque el uso dependerá de la divinidad” (2003, p. 610).

Se pone de manifiesto, entonces, que en la manera de comprender el camión, el objeto en Buenos Aires, -como paradigma de la lógica occidental- se afirma al camión en 
cuanto tal, mientras que en el caso de Eucaliptus -como paradigma del pensamiento indígena- el camión es sumergido en el horizonte de la negación, en el que se duda no del camión en sí mismo, sino de la posibilidad de usarle, de su utilidad como objeto. En ese sentido, la positividad de la que puede estar cargado el hecho de la compra de un camión en Eucaliptus está a su vez inmersa en la incertidumbre de un 'no', de manera que el uso de la 'cosa' en Buenos Aires es diferente en Eucaliptus, aunque se trate del mismo objeto. Esta negatividad de las cosas es propia de la sociedad y de la existencia misma, como Kusch afirma, pues la existencia en cierta forma es ser posible, lo que a su vez enmarca la existencia o la posibilidad de la misma en los proyectos, en cuanto ser posible, de tal forma que: "mi vivir está montado sobre su realización y ante todo sobre el supuesto de que es posible. Y esto, a los fines del puro vivir, basta. No entra en ello la propuesta científica" (2003, p. 611). No cabe la propuesta científica por el hecho mismo de la negación, pues esta es tomada como punto de partida y no la afirmación, de tal forma que las circunstancias que se oponen al proyecto de ser son la base del existir. De manera que es en la negación y no en la afirmación donde se da la posibilidad de ser, dado que esta última es la afirmación misma de la verdad como totalización del ser a partir de la negación de las circunstancias (2003, p. 612).

Ahora bien, la realización del proyecto existencial es siempre posibilitada por un horizonte simbólico de la cultura a la que se pertenece, esta da la totalización "correcta" y es correcta tanto la aimara como la occidental. Así, el puro existir, es decir, el estar con el asedio de la negación y las circunstancias, se convierte en el punto de arranque del proyecto existencial. La lógica del vivir es una "lógica simétricamente invertida" a la científica y es por esto mismo que la existencia es condición para el pensar (Heidegger, 2005, p. 613).

Es así como la realidad en el pensamiento aimara es re-presentada por medio, en y a través del "sacrificio", de la celebración y el ritual, pues para lograr la verdad, la cosa-Die Sache-debe someterse a la negación y en todos estos casos se parte de una negación que subyace en la experiencia existencial. Parece, entonces, que esta lógica del vivir crea trampas lógicas para alcanzar la revelación "re-presentación” (Kusch, 2003, p. 614), evidenciando la búsqueda interior frente al asedio negativo del mundo y esta búsqueda no termina en las cosas -Das Ding-, pues la negación de las cosas transforma al mundo en símbolos y las "plegarias” y celebraciones -el campo de los dioses- satisfacen el requerimiento mismo de la verdad. Así, "esa teología popular es una forma de llenar con algún género de racionalización la pregunta abierta por 
la verdad" (p. 614). Es precisamente la persistencia en aquello "teológico", aquello que pertenece al campo de la plegaria, en donde el camión se reduce como objeto a ser simplemente una parte de la totalidad del rito.

Justamente en ese mismo sentido interpretativo del pensar indígena y particularmente aimara apuntan las investigaciones del filósofo Josef Estermann, quien afirma que:

Para la filosofía andina, la 'realidad' está presente (o se presenta) en forma simbólica, y no tanto representativa o conceptual. El primer afán del runa/ jaqui andino no es la adquisición de un 'conocimiento' teórico y abstractivo del mundo que le rodea, sino la 'inserción mítica y la (re-)presentación cúltica y ceremonial simbólica de la misma. La realidad se 'revela' en la celebración de la misma, que es más una reproducción que una re-presentación, más un 're-crear' que un 're-pensar' (2006, p. 105).

Es evidente que esta forma de 'presentación' de la realidad en Occidente es tomada como actitud 'mágica', 'mitológica' y hasta 'preconceptual'. Sin embargo, más allá de los prejuicios epistemológicos occidentales, esta forma de 'revelación' de la realidad a través de lo cúltico plantea ciertos aportes a la epistemología en general, particularmente superando la dualidad entre sujeto-objeto que ha dado como resultado praxeológico el dominio del sujeto sobre todo aquello que ha pretendido objetivar y posteriormente dominar (Radford, 1993).

\section{Relacionalidad del todo como principio epistemológico}

El pensamiento occidental es "esencialista-sustancialista" y las expresiones epistemológicas de la realidad que le son propias, son por definición consustanciales, es decir, el principio - arjé- de la realidad es el ente y este en tanto sustancia -finita o infinita-. Si bien, la noción de sustancia es relacional, no es propiamente una relación, -lo que para Aristóteles era un accidente-, pues solo puede definírsele en contraste con su opuesto, lo accidental. Este último subsiste en otro, es en otro, mientras que la sustancia es en sí misma.

6 La idea de $\theta \varepsilon \delta \varsigma-\lambda o \gamma o \varsigma$, está relacionada con la tradición logocéntrica de Occidente, sin embargo, dada la salvedad, nos servimos de esta idea "puente" para la comprensión del pensamiento andino. 
En el caso andino, el arjé no es propiamente una sustancia, sino la relación misma, de tal suerte que "la relación es - para hablar en forma paradójica- la verdadera 'sustancia' Andina” (2006, p. 109). Es tal la naturaleza de esta relacionalidad "primordial" que todas las cosas son, en sí mismas, entendidas como relación; no solo están en relación -como un accidente a la sustancia-, sino que son relación. Por supuesto que esta ontología de la relación no es una particularidad del pensar andino, sino del pensar en sí mismo, así lo percibió también Martín Heidegger, cuando cuestionándose por la naturaleza de la relación entre el ser y la ex-sistencia, afirmó:

El propio ser es la relación, en cuanto él es el que mantiene junto a sí a la exsistencia en su esencia existencial, es decir, extática, y la recoge junto a sí como el lugar de la verdad del ser en medio de lo ente (2007, p. 273).

En este punto puede comprenderse el papel fundamental de lo simbólico en el mundo andino, particularmente en las expresiones cúlticas, celebrativas y sacramentales, pues estas permiten representar la relacionalidad que subyace en la comprensión de la realidad. Podemos decir que lo que se interpreta en la tradición occidental como “ente", es un punto de concreción de relaciones en la perspectiva andina?.

Sin profundizar en las implicaciones antropológicas de esta noción de la relacionalidad en contraste con la racionalidad moderno/colonial, vale la pena recordar la importancia que en el pensamiento occidental tiene la idea de individuo, noción que en el pensamiento andino sería un "nada" en el pleno sentido de la palabra, es decir, un "no-ente", pues lo ente, como se ha mencionando, es el nudo relacional mismo (Estermann, 2006).

Subyace entonces una determinada racionalidad, un determinado acercamiento a la realidad, que no es propiamente el distanciamiento gnoseológico de la epistemología clásica de Occidente, entre otras, distanciamiento que se puede rastrearse justamente en la expresión de "epistemología", término que privilegia el sentido de la vista que permite mantener la distancia de lo observado. Por su parte, la 'racionalidad' amerindia privilegia otras facultades no visuales como el tacto y el olfato, entre otros

7 Al respecto, en la tradición de la filosofia occidental es Leibniz quien más se aproxima a la noción de relación que se da en el pensar andino, pues para este filósofo la relación es intrínseca a la sustancia y no mero accidente de la misma, lo que concibió como "mónada". 
elementos indispensables en los rituales ceremoniales y que aún subyacen en los modelos de relacionamiento de los ancianos criollos e indígenas. De esta manera:

El runa/jaqui 'escucha' la tierra, el paisaje y el cielo; 'siente' la realidad mediante el corazón [...] La sensibilidad y sensitividad andinas no dan preferencia al 'ver', y por lo tanto, la racionalidad cognoscitiva no es en primer lugar 'teorética' (theorein), sino más bien emocio-afectiva (Estermann, 2006, p. 114).

Esta aproximación andina basada en el sentimiento, lo emocional y celebrativo a la realidad no es propiamente una "irracionalidad" mitológica como algunos puristas de la filosofía pretenden insinuar. La razón es, entonces, solo una ayudante para la "comprensión" siempre y cuando esté corroborada por ciertas capacidades "no-racionales" que no son "irracionales" sino "meta racionales" (p.114), en tanto que los 'entes' son concretos en cuanto interrelacionados -no propiamente en la forma del monísmo filosófico-.

La relación "teológica" y/ sacramental con el objeto -camión- pone de manifiesto que el pensar indígena se ubica en un vector distinto al que se da en la ciudad, -como paradigma occidental-. A diferencia de lo que ocurre en este último, predomina el área de la plegaria, es decir, la elección por los dioses 'innombrables', sobre la típica relación sujeto-objeto (Kusch, 2003), vista tradicionalmente como una evolución en relación con la actitud teológica. Sin embargo, Kusch se aventura a preguntarse por las posibilidades de la superación de la exclusión de los vectores:

¿Pero qué pasaría si partimos de la tesis de que no hay una exclusión de un vector a otro a medida que pasa el tiempo, porque esta forma de pensar pertenece a un mito colectivo del pensar occidental, y que en cambio en ningún momento se excluyen los vectores sino que subsisten? (2003, p. 615).

Esta subsistencia de vectorialidades se evidencia en manifestaciones populares como el porte de amuletos, los múltiples mitos políticos y científicos que seguramente pretenden ser el disfraz de la plegaria en la ciudad. $Y$ es que precisamente es en el pensamiento criollo en el que se constituye una conciliación entre los dos vectores de manera más notoria, excluyéndose la posibilidad de una evolución de un vector a otro, pues "lo criollo concilia ambos porque salva todo lo referente a las cosas, o sea a la relación sujeto-objeto, aunque a nivel de picardía, de tal modo que igual sostiene el otro vector, como un área de la plegaria” (p. 616). El filósofo argentino se 
cuestiona si la filosofía o la creación de los sistemas filosóficos dependen en parte de qué vector se carga de significado. Siendo cierta la doble vectorialidad del pensar, se muestra cómo el campesino invierte la relación con respecto a Occidente, pues en él predomina la apertura a los dioses sobre la tendencia yo-mundo -sujeto-objeto-, sin que esta quede de sí excluida.

\section{Referencias}

Bruhl-Lévy, L. (2003). El alma primitiva. Barcelona: Península.

Díaz-Guzmán, V. (1991). Filosofía en el Antiguo Perú. Lima: Nosotros.

Duvilios, P e Itier, C. (1993). Joan de Santa Cruz Pachacuti Yamqui Salcamaugua. Relación de Antigüedades deste reymo del Piru; estudio etnohistórico y lingüístico. Cusco: Institut Francais D'Études Andines; Centro de Estudios Regionales Andinos "Bartolomé de las Casas".

Estermann, J. (2006). Filosofía Andina; Sabiduría indígena para un mundo Nuevo. La Paz: ISEAT.

Estermann, J. (2008). Si el Norte fuera el Sur; Chakanas interculturales. La Paz: ISEAT.

Hegel, F. (1970). Vorlesungen über die Philosophie der Geschichte. En Werke in zwanzig Bänden. Tomo 12. Francfort/M.

Hegel, F. (1986). Lecciones sobre filosofía de la historia universal. Madrid: Alianza.

Heidegger, M. (2007). Carta sobre el humanismo. En Hitos. Madrid: Alianza.

Heidegger, M. (2005). ¿Qué significa pensar? Madrid: Trotta.

Heidegger, M. (2005). Ser y Tiempo. (J. Rivera, trad.). Santiago: Editorial Universitaria.

Kusch, R. (2003). Obras Completas. Tomo II. Rosario: Ross.

Mejía-Huamán, M. (2005). Hacia una Filosofía Andina; doce ensayos sobre el componente andino de nuestro pensamiento. [Primera edición computarizada]. Recuperado de www.filosofiaandina.com

Orrego, I. A. (2014). Ontología del tiempo espacio en el pensar abyayalense y la circunstancialización del ser. Diálogos con occidente. (Tesis de maestría Summa cum laude). Universidad Santo Tomás, Bogotá. 
Pacheco Farfán, J. (1994). Filosofía inka y su proyección al futuro. Cusco: San Antonio Abad.

Rivara de Tuesta, M. L. (1992). El pensamiento Incaico. En L. Robles (ed.). Filosofía Iberoamericana en la época del encuentro, (pp. 103-115). Madrid: Trotta.

Salazar-Bondy, A. (1978). Sentido y Problema del pensamiento filosófico Hispanoamericano. Cuadernos de Cultura Latinoamericana 12. 